\title{
Alginate microspheres obtained by the spray drying technique as mucoadhesive carriers of ranitidine
}

\author{
MARTA SZEKALSKA ${ }^{1}$ \\ ALEKSANDRA AMELIAN ${ }^{1,2}$ \\ KATARZYNA WINNICKA ${ }^{1^{*}}$ \\ ${ }^{1}$ Department of Pharmaceutical \\ Technology \\ Medical University of Białystok \\ 15-222 Białystok, Poland \\ ${ }^{2}$ Department of Clinical Pharmacy \\ Medical University of Białystok \\ 15-222 Biatystok, Poland
}

\begin{abstract}
The present study is aimed at formulation of alginate (ALG) microspheres with ranitidine (RNT) by the spray drying method. Obtained microspheres were characterized for particle size, surface morphology, entrapment efficiency, drug loading, in vitro drug release and zeta potential. Mucoadhesive properties were examined by a texture analyser and three types of adhesive layers - gelatine discs, mucin gel and porcine stomach mucosa. Microspheres showed a smooth surface with narrow particle size distribution and RNT loading of up to $70.9 \%$. All formulations possessed mucoadhesive properties and exhibited prolonged drug release according to the first-order kinetics. DSC reports showed that there was no interaction between RNT and ALG. Designed microspheres can be considered potential carriers of ranitidine with prolonged residence time in the stomach.
\end{abstract}

Keywords: ranitidine, sodium alginate, microspheres, spray drying technique, mucoadhesiveness

Ranitidine (RNT) is a widely used histamine receptor antagonist, which inhibits gastric acid secretion by parietal cells induced by gastrin, histamine and cholinergic stimulation. It is mainly used in the treatment of gastro-oesophageal reflux disease, gastric and duodenal ulceration and Zollinger-Ellison syndrome. However, after administration in conventional dosage forms, RNT has low bioavailability (below $50 \%$ ), because it is poorly absorbed and degraded by intestinal bacteria in the lower segment of the gastrointestinal tract (1-3).

Dosage forms with prolonged gastric residence time are particularly suitable for drugs that are absorbed in the stomach, which are unstable in the intestines or are poorly soluble at high $\mathrm{pH}$. Prolongation of drug residence time in the stomach can be achieved by floatation, mucoadhesion, by modifying the shape of drug carrier, by swelling and high-density systems or by co-administration of a pharmacological agent delaying gastric emptying. Floatation requires the presence of a liquid, on which the dosage form can float in the presence of gastric contents. To overcome this limitation and to prolong residence time

\footnotetext{
*Correspondence; e-mail: kwin@umb.edu.pl
} 
of the dosage form in the stomach, mucoadhesive polymers are used. Mucoadhesive polymers bind to the gastric epithelial cell surface or mucin and provide sustained residence time in the stomach and, as a consequence, improve drug bioavailability $(4,5)$. Mucoadhesive microspheres are considered as a promising drug delivery system. This multiparticulate dosage form provides improved efficacy, reduced toxicity and a wider margin of safety in the case of dosage form damage, compared to traditional single unit formulations (6-8).

To produce microspheres with mucoadhesive properties, natural polymers (gelatin, chitosan, tragacanth, alginates) are mainly used. Sodium alginate (ALG) is a non-toxic, biocompatible, biodegradable polymer, which belongs to the polysaccharides naturally present in seaweed $(9,10)$. Contact of ALG with the acidic environment in the stomach leads to the formation of a gel layer that has a protective effect on the mucous membranes of the stomach and oesophagus. ALG is therefore an ingredient of many medications (antacids) commonly used in the treatment of heartburn and reflux diseases $(11,12)$.

As mucoadhesive microspheres offer a unique carrier system for many pharmaceuticals, much research work has been done in the last decade on their application to various routes. The gastrointestinal tract is the most important route for drug administration and therefore oral mucoadhesive dosage forms have been extensively studied. Mucoadhesive microspheres have been reported to increase the peroral bioavailability of many drugs, including metformin, amoxicillin, ibuprofen, furosemide, insulin, glipizide, acyclovir, captopril, and dicumarol (6-8). Microspheres can be prepared by several methods: single emulsion, solvent evaporation, cross-linking, or spray drying, but the choice mainly depends on the nature of the polymer, the drug and the intended use. To our best knowledge, there are no studies devoted to the formulation of mucoadhesive microspheres with RNT by the spray drying technique. This is a new method for the preparation of microparticles and the physicochemical properties of the final product mainly depend on the inlet temperature, air flow rate, feed flow rate, atomizer speed, type of the polymer, properties of the drug, and polymer/drug ratio (13). Therefore, the aim of this study was to design and produce mucoadhesive ALG microspheres with RNT by spray drying. The obtained microspheres were tested in vitro to select the optimum formulation with favourable mucoadhesive properties and prolonged RNT release. In adition, the effect of ALG:RNT ratios and different concentrations of ALG solution were investigated.

\section{EXPERIMENTAL}

\section{Materials}

Ranitidine hydrochloride was obtained from Zakłady Farmaceutyczne Polpharma S.A. (Poland). Sodium alginate of low viscosity (viscosity of $2 \%$ water solution: $0.1-0.3 \mathrm{~Pa}$ s) was purchased from Sigma Aldrich (Germany). Potassium dihydrogenphosphate, sodium hydroxide, hydrochloric acid and methanol were obtained from Chempur (Poland). Water was distilled and passed through a reverse osmosis system Milli-Q Reagent Water System (Millipore, USA). In order to examine the mucoadhesive properties, adhesive layers made of mucin type II from porcine stomach and gelatine type B from bovine skin (Sigma Aldrich) were prepared. Porcine stomach mucosa of large white pigs weighing ca $200 \mathrm{~kg}$ 
was obtained from the veterinary service (Turośń Kościelna, Poland). Samples were stored at $-20^{\circ} \mathrm{C}$ and were defrosted before the experiment and cut into 5-mm and 2-mm thick pieces.

\section{Preparation of microspheres}

Microspheres were prepared using a Büchi Mini Spray Dryer B-290 (Büchi, Schwitzerland). In order to choose the optimal spray drying parameters to obtain the product of desired properties, a number of tests were conducted and the experimental parameters of the process were set as follows: inlet temperature $127^{\circ} \mathrm{C}$, aspirator flow $37 \mathrm{~m}^{3} \mathrm{~h}^{-1}$, feed flow

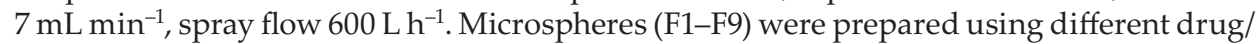
polymer mass ratios (1:1, 1:2, 2:1) and different concentrations of ALG solution (1, 2 and 3 \%) (Table I).

Table I. Composition of feed solutions used to prepare microspheres by spray drying

\begin{tabular}{ccc}
\hline $\begin{array}{l}\text { RNT:ALG } \\
\text { mass ratio }\end{array}$ & RNT $(\mathrm{g})$ & ALG $(\mathrm{g})$ \\
\hline \multicolumn{3}{c}{ 1\% ALG solution $(500 \mathrm{~mL})$} \\
$1: 1$ & 5 & 5 \\
$2: 1$ & 5 & 10 \\
& 10 & 5 \\
$1: 1$ & \% ALG solution $(500 \mathrm{~mL})$ & \\
$1: 2$ & 10 & 10 \\
$2: 1$ & 10 & 20 \\
& 20 & 10 \\
$1: 1$ & $3 \%$ ALG solution $(500 \mathrm{~mL})$ & 15 \\
$1: 2$ & 15 & 30 \\
$2: 1$ & 15 & 15 \\
\hline
\end{tabular}

\section{Evaluation of microspheres}

Morphology and particle size distribution. - Measurements of the particle size and mean microsphere diameter were performed using an optical microscope Motic BA400 (Motic, Germany) and Zetasizer NanoZS90 (Malvern Instruments, UK). Morphology of the microspheres was examined with a scanning electron microscope (SEM) (Hitachi S4200, Japan).

HPLC analysis of RNT. - The concentration of RNT in the medium was determined using the HPLC system Agilent Technologies 1200 equipped with a G1312A binary pump, a G1316A thermostat, a G1379B degasser and a G1315B diode array detector (Agilent, Germany). Data collection and analysis were performed using the Chemstation 6.0 software. Isocratic separation was achieved on a Zorbax Eclipse XDB-C18, 4.6×150 mm, 5- $\mu \mathrm{m}$ column (Agilent). Mobile phase was methanol/0.01 $\mathrm{mol} \mathrm{L}^{-1}$ phosphate buffer $\mathrm{pH} 7.0$ (1:3; V/V), the flow rate was $1.0 \mathrm{~mL} \mathrm{~min}^{-1}$ and UV detection was performed at $224 \mathrm{~nm}$ (14). Column temperature was maintained at $25^{\circ} \mathrm{C}$. For injection into the HPLC system, $20 \mu \mathrm{L}$ of sample 
was used. All reagents used for analysis were of HPLC grade. The retention time of RNT was $3.0 \mathrm{~min}$. The HPLC method was validated and the standard calibration curve was linear over the range of $1-100 \mu \mathrm{g} \mathrm{mL} \mathrm{m}^{-1}$ with the coefficient of determination $\left(R^{2}\right)$ of 0.999 .

RNT loading, encapsulation efficiency and production yield. - RNT loading in the microspheres was determined by dissolving an accurately weighed amount of microspheres (20 $\mathrm{mg}$ ) in $10 \mathrm{~mL}$ distilled water and agitating it for $24 \mathrm{~h}$ at $150 \mathrm{rpm}$ in a water bath (15). After filtration through a $0.45-\mu \mathrm{m}$ cellulose acetate Millipore filter (Millipore), RNT concentration was determined by HPLC. Each sample was analysed in triplicate.

Zeta potential. - Zeta potential measurements were performed using a Zetasizer NanoZS90 (Malvern Instrument). Microspheres were suspended in methanol before the measurement and data were received directly from Zetasizer Software 6.20. Zeta potential analysis is a technique for evaluation of the particle surface charge in the solution. It is an important tool for determining the state of the microsphere surface and it is directly related to the stability of the microsphere suspension. Microspheres with zeta potential values greater than $+25 \mathrm{mV}$ or less than $-25 \mathrm{mV}$ are characterized by high stability. Conversely, if the particles' zeta potential is relatively small, the particles will agglomerate (16).

Swelling properties. - Microspheres $(20 \mathrm{mg})$ were placed in beakers containing $25 \mathrm{~mL}$ of $0.1 \mathrm{~mol} \mathrm{~L}^{-1} \mathrm{HCl}(\mathrm{pH} 1.2)$ and stirred at $100 \mathrm{rpm}$ at $37 \pm 1^{\circ} \mathrm{C}$. At predetermined time intervals, the medium was carefully removed by filtration, and swollen microspheres were weighted. Swelling ratio (SR) is an important parameter to be studied before considering mucoadhesion and in vitro drug release. Swelling is the first step in the mucoadhesion process and it enables formation of bonds between the polymer and mucous membrane and consequently a spatial network with adhesive properties (17).

Mucoadhesive properties. - TA.XT.Plus Texture Analyser (Stable Microsystems, UK) equipped with a 5-kg load cell, cylinder probe and the measuring system A/MUC was used for mucoadhesion test. Mucoadhesive properties were assessed using three different types of mucoadhesive material: gelatin, mucin and porcine stomach mucosa. Porcine stomach mucosa model is often used to imitate in vivo conditions due to the similarity in the structure of human and porcine stomachs. Moreover, it was found that the differences in detachment forces between human and porcine gastric mucosa were not significant (18). Experimental parameters were chosen during preliminary tests and set as follows: pretest speed $0.5 \mathrm{~mm} \mathrm{~s}^{-1}$, test speed $0.1 \mathrm{~m} \mathrm{~s}^{-1}$, contact time $180 \mathrm{~s}$, post test speed $0.1 \mathrm{~mm} \mathrm{~s}^{-1}$, applied force $1 \mathrm{~kg} \mathrm{~m} \mathrm{~s}^{-2}$. Gelatin discs were prepared by pouring $30 \%(\mathrm{~m} / \mathrm{m})$ gelatin aqueous solution into a Petri dish. The layer of mucin was prepared by absorbing $10 \%$ mucin gel on a disc with cellulose fiber ( $5 \mathrm{~mm}$ in diameter). Tests were conducted at $37 \pm 1^{\circ} \mathrm{C}$. The mucoadhesive material was glued to an upper probe with $\alpha$-cyanoacrylate glue and was moisturized with $20 \mu \mathrm{L}$ of $0.1 \mathrm{~mol} \mathrm{~L}^{-1} \mathrm{HCl}$ (pH 1.2) (except for mucin gel) (19, 20). The microsphere mucoadhesive properties were determined as the maximum detachment force $\left(F_{\max }\right)$ and the work of mucoadhesion $\left(W_{\mathrm{ad}}\right)$ calculated from the area under the force versus distance curve, expressed in $\mu \mathrm{J}$ (21).

In vitro RNT release. - RNT release profiles were obtained according to the modified USP method (22) using a dissolution basket apparatus (Erweka Paddle Dissolution tester type DT $600 \mathrm{HH}$, Erweka, Germany). In each study, the amount of microspheres equivalent to $75 \mathrm{mg}$ of RNT was analysed. All microsphere formulations were suspended in $500 \mathrm{~mL}$ of $0.1 \mathrm{~mol} \mathrm{~L}^{-1} \mathrm{HCl}\left(\mathrm{pH}\right.$ 1.2) and stirred at $50 \mathrm{rpm}$ at $37 \pm 1{ }^{\circ} \mathrm{C}$ for $8 \mathrm{~h} \mathrm{(23).} \mathrm{Samples} \mathrm{were}$ withdrawn and filtered through a $0.45-\mu \mathrm{m}$ cellulose acetate filter (Millipore) at predeter- 
mined time intervals and replaced with fresh dissolution medium. The amount of released RNT was analysed by HPLC (as described earlier). The studies were carried out in triplicate.

\section{Mathematical modelling of RNT release profile}

RNT release data was analysed according to the zero-order kinetics, first-order kinetics, Higuchi model and Korsmeyer-Peppas equation to characterize the mechanism of drug release. The constants of release kinetics and $R^{2}$ coefficients were calculated from the slope of plots by linear regression analysis.

Zero-order kinetics is described by the formula:

$$
F=k t
$$

First-order kinetics is described by the formula:

$$
\ln F=k t
$$

Higuchi model is described by the equation:

$$
F=k \sqrt{t}
$$

and Korsmeyer-Peppas model is expressed by the following equation:

$$
F=k t^{n}
$$

where $F$ is the fraction of drug release, $k$ is the release constant and $t$ is time. For the Korsmeyer-Peppas model, the fraction of drug remaining at time $t$ was determined for every time interval from $\log \left(M_{t} / M_{\infty}\right)$ and plotted against the log of time $t$. The slope of the line was taken as the value of $n$-diffusion release exponent used for interpretation of the release mechanism. When $n$ takes a value below 0.43 for sphere shape, the drug diffuses through and is released from the polymer matrix following Fickian diffusion, $n=0.85$ indicates swelling-controlled release, $n$ between 0.43 and 0.85 - the mechanism of drug release, includes both phenomena (anomalous transport) $(24,25)$.

\section{Differential scanning calorimetric studies}

Differential scanning calorimetric (DSC) analysis of RNT, ALG and formulation F6 of microspheres (with the highest RNT loading) was performed using an automatic thermal analyser system (DSC TEQ2000, TA Instruments, USA). Each sample was precisely weighed ( $5 \mathrm{mg})$ and placed in a sealed aluminium pan. An empty sealed pan was used as reference. Temperature calibrations were performed using indium and zinc as standards. Samples were heated from 25 to $200{ }^{\circ} \mathrm{C}$ at a scanning rate of $10{ }^{\circ} \mathrm{C} \mathrm{min}{ }^{-1}$ under nitrogen flow of $20 \mathrm{~mL} \mathrm{~min}^{-1}(26)$.

\section{Statistical analysis}

Statistical analysis was performed using IBM SPSS Statistics 20. The strength and direction of correlation between the amount of RNT and the swelling ratio were assessed by Spearman correlation. 


\section{RESULTS AND DISCUSSION}

\section{Characterization of microspheres}

In the present study, RNT loaded microspheres were prepared by the spray drying method using ALG as the polymer matrix. Characteristics of the obtained formulations F1 -F9 are shown in Table II. Comparison of the particle size indicates that an increased amount of incorporated RNT resulted in a larger microsphere particle size. Microspheres F1, with the lowest RNT loading ( $32.4 \pm 1.8 \%$ ) have the mean diameter of $0.9 \pm 0.1 \mu \mathrm{m}$, but microspheres F6 with the highest RNT loading (70.9 $\pm 1.5 \%) 2.6 \pm 0.1 \mu \mathrm{m}$. When the concentration of ALG solution was increased, microspheres were significantly larger, but the production yield was decreased ranging from $67.3 \pm 1.7 \%$ (F1) to $32.7 \pm 2.2 \%$ (F9).

Table II. Composition and properties of RNT-loaded ALG microspheres

\begin{tabular}{ccccccc}
\hline $\begin{array}{c}\text { Formu- } \\
\text { lation }\end{array}$ & $\begin{array}{c}\text { RNT/ALG } \\
\text { ratio } \\
(\mathrm{m} / \mathrm{m})\end{array}$ & $\begin{array}{c}\text { Zeta } \\
\text { potential } \\
(\mathrm{mV})^{\mathrm{a}}\end{array}$ & $\begin{array}{c}\text { Production } \\
\text { yield } \\
(\%)^{\mathrm{a}}\end{array}$ & $\begin{array}{c}\text { Encapsulation } \\
\text { efficiency } \\
(\%)^{\mathrm{a}}\end{array}$ & $\begin{array}{c}\text { RNT } \\
\text { loading } \\
(\%)^{\mathrm{a}}\end{array}$ & $\begin{array}{c}\text { Mean } \\
\text { diameter } \\
(\mu \mathrm{m})^{\mathrm{a}}\end{array}$ \\
\hline F1 & $1: 2$ & $-40.7 \pm 7.2$ & $67.3 \pm 1.7$ & $95.6 \pm 2.1$ & $32.4 \pm 1.8$ & $0.9 \pm 0.1$ \\
F2 & $1: 1$ & $-26.9 \pm 6.5$ & $61.3 \pm 2.4$ & $90.8 \pm 2.7$ & $49.2 \pm 3.5$ & $1.7 \pm 0.9$ \\
F3 & $2: 1$ & $-28.4 \pm 5.4$ & $40.7 \pm 1.4$ & $81.9 \pm 3.2$ & $66.2 \pm 1.7$ & $2.2 \pm 0.1$ \\
& & & $2 \%$ ALG solution & & \\
F4 & $1: 2$ & $-38.2 \pm 2.2$ & $47.3 \pm 1.6$ & $85.4 \pm 1.9$ & $37.6 \pm 2.2$ & $1.6 \pm 0.1$ \\
F5 & $1: 1$ & $-35.9 \pm 1.1$ & $44.9 \pm 1.3$ & $80.3 \pm 2.1$ & $55.2 \pm 3.6$ & $2.2 \pm 0.1$ \\
F6 & $2: 1$ & $-30.5 \pm 3.9$ & $36.8 \pm 2.1$ & $79.5 \pm 2.3$ & $70.9 \pm 1.5$ & $2.6 \pm 0.1$ \\
& & & $3 \%$ ALG solution & & $1.9 \pm 0.1$ \\
F7 & $1: 2$ & $-52.9 \pm 4.4$ & $36.6 \pm 1.1$ & $77.6 \pm 2.7$ & $49.1 \pm 3.9$ & $2.5 \pm 0.1$ \\
F8 & $1: 1$ & $-38.6 \pm 1.6$ & $39.2 \pm 1.4$ & $70.4 \pm 2.9$ & $57.2 \pm 3.9$ & $2.6 \pm 0.1$ \\
F9 & $2: 1$ & $-33.6 \pm 2.6$ & $32.7 \pm 2.2$ & $67.8 \pm 3.1$ & $65.1 \pm 7.5$ & 2.9 \\
\hline
\end{tabular}

${ }^{\mathrm{a}}$ Mean $\pm \mathrm{SD}, n=3$.

The drug/polymer ratio is a key factor influencing the characteristics of microspheres. The minimum RNT loading was observed in formulation F1 (drug/polymer ratio 1:2, $1 \%$ ALG solution) and maximum in F6 (drug/polymer ratio 2:1, $2 \%$ ALG solution). The increase in the drug/polymer ratio resulted in an improvement of RNT loading, but encapsulation efficiency was decreased.

The SEM photographs of microspheres showed that the obtained particles were spherical (Fig. 1).

\section{Zeta potential}

All formulations showed a negative zeta potential value (from $-26.9 \mathrm{mV}$ in F2 to -52.9 $\mathrm{mV}$ in F7), which indicated their stability (Table II). The negative value of zeta potential is a result of the negative charge of ALG. 

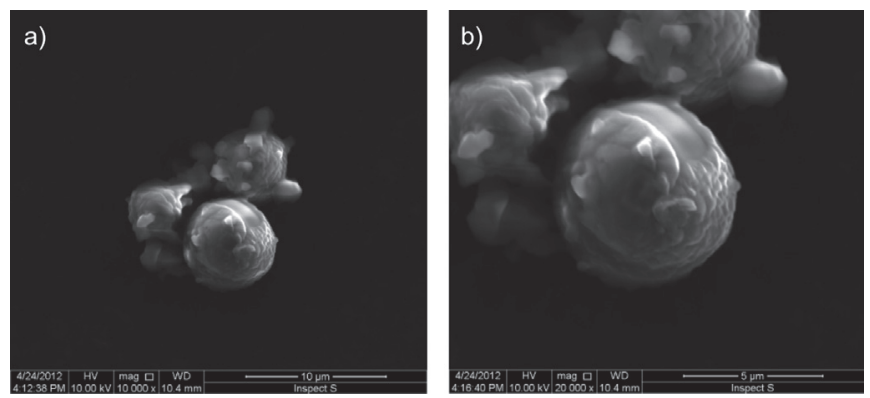

Fig. 1. SEM images of microspheres formulation F6 under magnification of: a) 10,000×, b) 20,000×.

\section{Swelling and mucoadhesive properties}

In this study, swelling properties were examined in $0.1 \mathrm{~mol} \mathrm{~L}^{-1} \mathrm{HCl}$ at $\mathrm{pH}$ 1.2. As shown in Fig. 2, the medium penetrates through the pores of microspheres and the initial rapid rise in swelling ratio was observed in all formulations after the first $30 \mathrm{~min}$. The linear increase in SR was observed up to $240 \mathrm{~min}$. RNT/ALG ratio had a significant effect on the swelling properties of obtained microspheres.

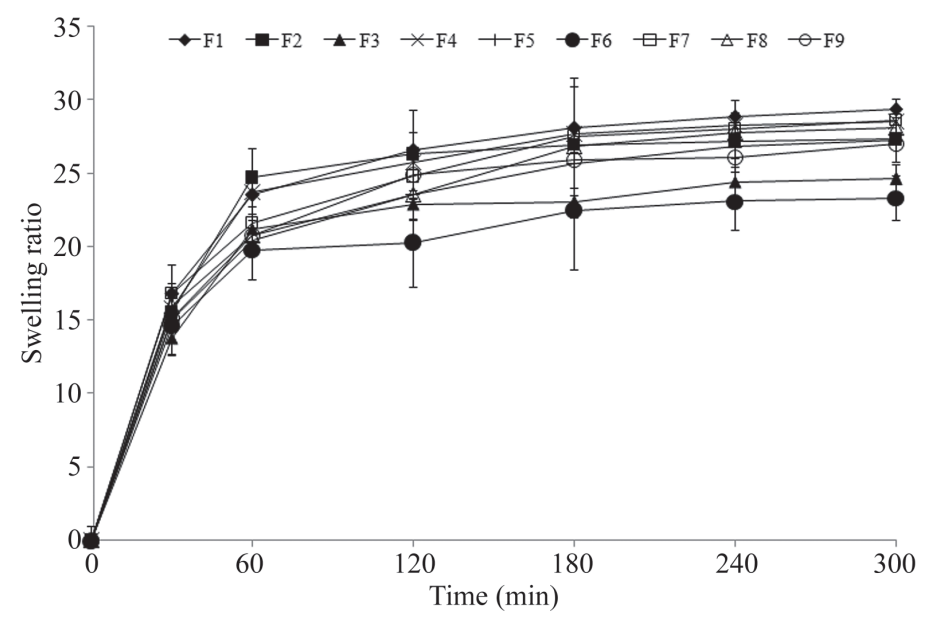

Fig. 2. Swelling ratio of microsphere formulations F1-F9 (mean $\pm \mathrm{SD}, n=3$ ).

To investigate if the presence of the drug in microspheres F1-F9 influenced the polymer swelling ability, the amount of polymer was correlated with the swelling ratio. The strength and direction of correlation were assessed by Spearman correlation. With increasing the amount of ALG, SR was significantly increased. With the increase of swelling time (300 $\mathrm{min})$, a higher correlation coefficient and lower $p$-value $(p<0.001)$ were reported (Fig. 3). Based on the obtained results, high positive, significant $(p<0.05)$ correlation coefficients (between 0.73 and 0.95 ) were observed in all time series (Table III). 


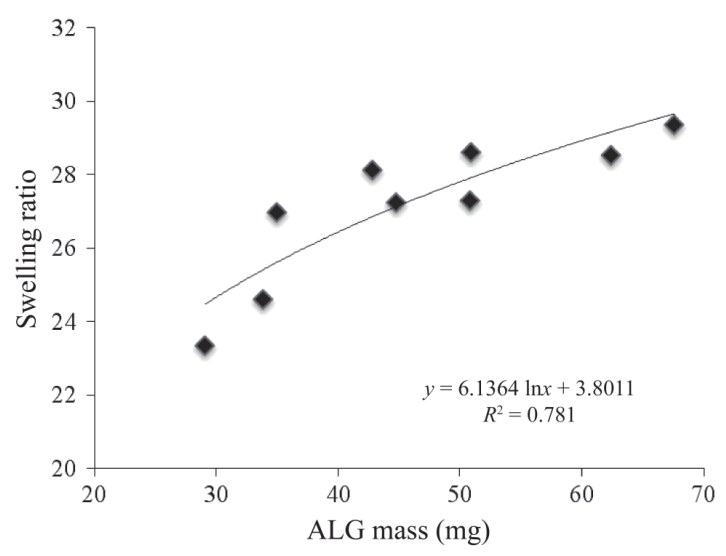

Fig. 3. Correlation between the amount of ALG in microspheres and swelling ratio observed after $300 \mathrm{~min}$.

Table III. Correlations between the amount of alginate and swelling ratio in examined time series

\begin{tabular}{ccc}
\hline Time $(\mathrm{min})$ & $R$ & $p$ \\
\hline 30 & 0.783 & 0.013 \\
60 & 0.733 & 0.025 \\
120 & 0.833 & 0.005 \\
180 & 0.950 & $<0.001$ \\
240 & 0.950 & $<0.001$ \\
300 & 0.933 & $<0.001$ \\
\hline
\end{tabular}

$R$ - correlation coefficient

$p$ - level of significance

SR - swelling ratio

Mucoadhesive properties of microsphere formulations F1-F9 were investigated with a texture analyser and are presented as maximum detachment force $\left(F_{\max }\right)$ and work of adhesion $\left(W_{\mathrm{ad}}\right)$ (Table IV). Gelatin discs, mucin gel and porcine stomach mucosa were used as adhesive layers. All examined formulation showed mucoadhesive properties expressed as $F_{\max }$ with the range of $0.16 \pm 0.02 \mathrm{~kg} \mathrm{~m} \mathrm{~s}^{-2}$ to $0.91 \pm 0.06 \mathrm{~kg} \mathrm{~m} \mathrm{~s}^{-2}$ and $W_{\text {ad }}$ between $340.6 \pm$ 1.4 and $989.2 \pm 3.2 \mu \mathrm{J}$. In general, the strength of alginate mucoadhesive bond increased by decreasing the amount of RNT in the formulations.

Our study has shown a direct correlation between the mucoadhesive properties and SR in RNT microspheres with ALG. The highest values of $F_{\max }$ and $W_{\text {ad }}$ were observed for formulation F1, with the highest SR and minimum RNT loading (values obtained using porcine stomach mucosa: $F_{\max } 0.91 \pm 0.06 \mathrm{~kg} \mathrm{~m} \mathrm{~s}^{-2}$ and $\left.W_{\text {ad }} 989.2 \pm 3.2 \mu \mathrm{J}\right)$.

\section{In vitro $R N T$ release}

In vitro release studies of RNT were performed in $\mathrm{HCl}$ at $\mathrm{pH} 1.2$ for $8 \mathrm{~h}$. The data obtained for formulations F3, F6 and F9 (with the highest RNT loading) are shown in Fig. 4. 
M. Szekalska et al.: Alginate microspheres obtained by the spray drying technique as mucoadhesive carriers of ranitidine, Acta Pharm. 65 (2015) 15-27.

Table IV. Mucoadhesive properties of microspheres formulations F1-F9

\begin{tabular}{|c|c|c|c|c|c|c|}
\hline \multirow{3}{*}{$\begin{array}{l}\text { Formu- } \\
\text { lation }\end{array}$} & \multicolumn{6}{|c|}{ Type of adhesive layer ${ }^{\mathrm{a}}$} \\
\hline & \multicolumn{2}{|c|}{ Gelatine } & \multicolumn{2}{|c|}{ Mucin } & \multicolumn{2}{|c|}{ Porcine stomach mucosa } \\
\hline & $\begin{array}{c}F_{\max } \mathrm{b} \\
\left(\mathrm{kg} \mathrm{m} \mathrm{s}^{-2}\right)\end{array}$ & $\begin{array}{l}W_{\mathrm{ad}}{ }^{\mathrm{c}} \\
(\mu \mathrm{J})\end{array}$ & $\begin{array}{c}F_{\max } \\
\left(\mathrm{kg} \mathrm{m} \mathrm{s}^{-2}\right)\end{array}$ & $\begin{array}{l}W_{\mathrm{ad}}{ }^{\mathrm{c}} \\
(\mu \mathrm{J})\end{array}$ & $\begin{array}{c}F_{\max }{ }^{\mathrm{b}} \\
\left(\mathrm{kg} \mathrm{m} \mathrm{s}^{-2}\right)\end{array}$ & $\begin{array}{l}W_{\mathrm{ad}}{ }^{\mathrm{c}} \\
(\mu \mathrm{J})\end{array}$ \\
\hline $\mathrm{F} 1$ & $0.17 \pm 0.02$ & $628.8 \pm 0.3$ & $0.55 \pm 0.02$ & $605.4 \pm 0.7$ & $0.91 \pm 0.06$ & $989.2 \pm 3.2$ \\
\hline F2 & $0.16 \pm 0.02$ & $542.4 \pm 0.1$ & $0.49 \pm 0.04$ & $483.0 \pm 0.6$ & $0.59 \pm 0.05$ & $763.7 \pm 1.1$ \\
\hline F3 & $0.18 \pm 0.02$ & $509.5 \pm 0.3$ & $0.42 \pm 0.09$ & $340.6 \pm 1.4$ & $0.48 \pm 0.05$ & $770.3 \pm 1.7$ \\
\hline $\mathrm{F} 4$ & $0.21 \pm 0.01$ & $764.0 \pm 0.6$ & $0.78 \pm 0.04$ & $959.1 \pm 0.6$ & $0.70 \pm 0.07$ & $892.0 \pm 2.5$ \\
\hline F5 & $0.19 \pm 0.08$ & $528.0 \pm 1.5$ & $0.49 \pm 0.06$ & $774.8 \pm 0.7$ & $0.85 \pm 0.03$ & $770.9 \pm 0.6$ \\
\hline F6 & $0.19 \pm 0.03$ & $597.5 \pm 0.6$ & $0.55 \pm 0.08$ & $676.6 \pm 0.6$ & $0.76 \pm 0.04$ & $716.1 \pm 1.1$ \\
\hline F7 & $0.22 \pm 0.06$ & $829.8 \pm 2.7$ & $0.63 \pm 0.06$ & $828.8 \pm 0.6$ & $0.83 \pm 0.07$ & $905.9 \pm 1.5$ \\
\hline F8 & $0.19 \pm 0.07$ & $710.8 \pm 3.4$ & $0.63 \pm 0.09$ & $748.8 \pm 0.8$ & $0.79 \pm 0.04$ & $904.2 \pm 0.5$ \\
\hline F9 & $0.19 \pm 0.04$ & $694.5 \pm 2.5$ & $0.73 \pm 0.07$ & $739.2 \pm 0.6$ & $0.77 \pm 0.07$ & $812.5 \pm 0.8$ \\
\hline
\end{tabular}

${ }^{\mathrm{a}}$ Mean $\pm \mathrm{SD}, n=6$.

${ }^{\mathrm{b}}$ Maximum detachment force.

${ }^{\mathrm{c}}$ Work of adhesion.

After $0.5 \mathrm{~h}$, the burst effect was observed and RNT was continuously released up to $4-6 \mathrm{~h}$. The total amount of drug was released from formulations F3 and F6 after $4 \mathrm{~h}$, and from formulation F9 after $6 \mathrm{~h}$. Conversion of ALG at acidic $\mathrm{pH}$ to gelling alginic acid prevents matrix disintegration and controls water penetration inside the microsphere structure. The in vitro dissolution data were analysed by different kinetic models to find out the $n$ value and the coefficients of determination $\left(R^{2}\right)$ for the respective models (Table V). The values of $n$ for the release of RNT from the ALG microspheres range between 0.071 and

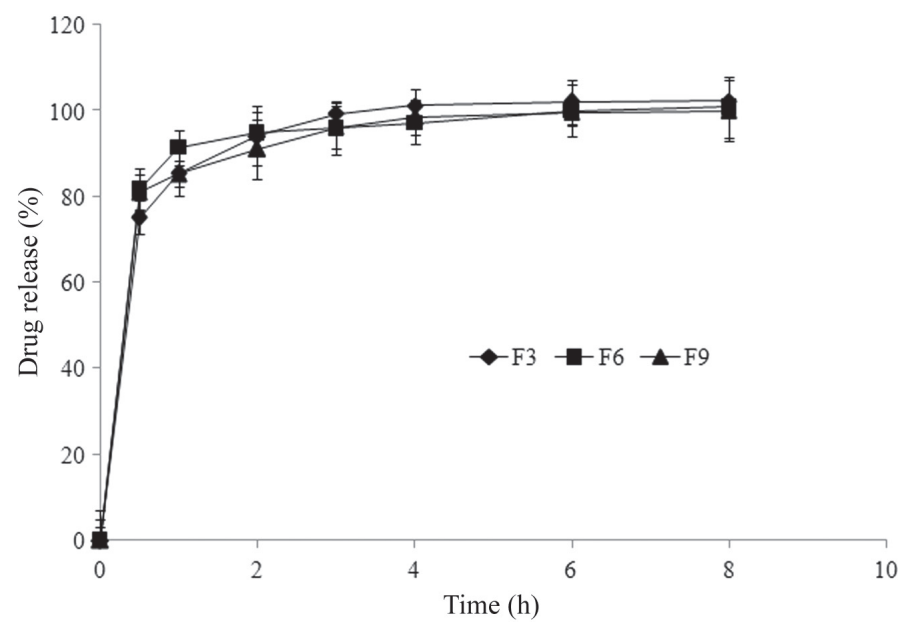

Fig. 4. RNT release from formulations $\mathrm{F} 3, \mathrm{~F} 6$ and $\mathrm{F} 9$ in $0.1 \mathrm{~mol} \mathrm{~L}^{-1} \mathrm{HCl}(\mathrm{pH} 1.2)($ mean $\pm \mathrm{SD}, n=3)$. 
0.182 indicating that the drug release followed the diffusion process. In all formulations, the highest value of $R^{2}$ was observed in the first-order kinetic model, which indicates that RNT release was concentration dependent (Table V).

Table V. Models of $R$ NT release in $0.1 \mathrm{~mol} \mathrm{~L}^{-1} \mathrm{HCl}$

\begin{tabular}{|c|c|c|c|c|c|c|c|c|c|}
\hline \multirow{2}{*}{$\begin{array}{l}\text { Formu- } \\
\text { lation }\end{array}$} & \multicolumn{2}{|c|}{$\begin{array}{l}\text { Zero-order } \\
\text { kinetics }\end{array}$} & \multicolumn{2}{|c|}{$\begin{array}{l}\text { First-order } \\
\text { kinetics }\end{array}$} & \multicolumn{2}{|c|}{$\begin{array}{l}\text { Highuchi } \\
\text { model }\end{array}$} & \multicolumn{3}{|c|}{$\begin{array}{c}\text { Korsmeyer-Peppas } \\
\text { model }\end{array}$} \\
\hline & $R^{2}$ & $k_{0}^{\mathrm{b}}$ & $R^{2}$ & $k_{\mathrm{I}}^{\mathrm{c}}$ & $R^{2}$ & $k_{\mathrm{H}}^{\mathrm{d}}$ & $R^{2}$ & $k_{\mathrm{KP}}$ & $n^{e}$ \\
\hline F1 & 0.341 & 1.255 & 0.989 & 0.309 & 0.855 & 17.64 & 0.946 & 0.401 & 0.182 \\
\hline F2 & 0.664 & 4.615 & 0.991 & 0.352 & 0.855 & 12.92 & 0.945 & 0.332 & 0.119 \\
\hline F3 & 0.471 & 1.113 & 0.953 & 0.618 & 0.802 & 12.19 & 0.922 & 0.328 & 0.116 \\
\hline F4 & 0.731 & 3.698 & 0.951 & 0.249 & 0.809 & 12.73 & 0.868 & 0.329 & 0.119 \\
\hline F5 & 0.945 & 4.148 & 0.936 & 0.243 & 0.890 & 11.24 & 0.947 & 0.309 & 0.105 \\
\hline F6 & 0.887 & 2.921 & 0.937 & 0.541 & 0.822 & 7.28 & 0.910 & 0.257 & 0.071 \\
\hline F7 & 0.336 & 0.662 & 0.935 & 0.383 & 0.867 & 10.93 & 0.940 & 0.306 & 0.103 \\
\hline F8 & 0.310 & 0.765 & 0.912 & 0.331 & 0.853 & 13.12 & 0.947 & 0.339 & 0.127 \\
\hline F9 & 0.354 & 0.577 & 0.990 & 0.313 & 0.891 & 9.35 & 0.964 & 0.279 & 0.085 \\
\hline
\end{tabular}

$R^{2}$ - coefficient of determination.

a Zero-order release constant.

${ }^{\mathrm{b}}$ First-order release constant.

${ }^{c}$ Constant reflecting the design variables of the system.

${ }^{\mathrm{d}}$ Constant reflecting the structural and geometric dosage form

e Release exponent.

\section{DSC studies}

The physical state of RNT inside the ALG microspheres was assessed by thermal analysis. DSC thermograms of RNT, ALG and formulation F6 (with the highest RNT loading) are shown in Fig. 5. Two types of polymorphic crystalline forms of RNT have been described in the literature. Form 1 exhibits considerable hygroscopicity and has its melting point between 134 and $140{ }^{\circ} \mathrm{C}$. Form 2 is more advantageous, it is easy to dry, less sensitive to moisture and is characterized by the melting point between 140 and $149^{\circ} \mathrm{C}(27)$. Under the experimental conditions, the DSC thermogram of pure RNT shows a sharp endothermic peak at $149.04{ }^{\circ} \mathrm{C}$, which indicates the presence of the polymorphic form 2 . The melting point of RNT is accompanied by exothermic degradation, which is related to the presence of the nitro moiety and produces a dark brown degradation product (28). The thermogram of formulation $\mathrm{F} 6$ shows the RNT peak at $142.90^{\circ} \mathrm{C}$, which demonstrates the presence of form 2. Moreover, reduction of the RNT melting point in formulation F6 might be due to its mixing with ALG, which lowered the purity of each component (29). Melting peak of ALG $\left(119.27^{\circ} \mathrm{C}\right)$ was not detected in F6, which might suggest that ALG had dehydrated during the spray drying process (30). 


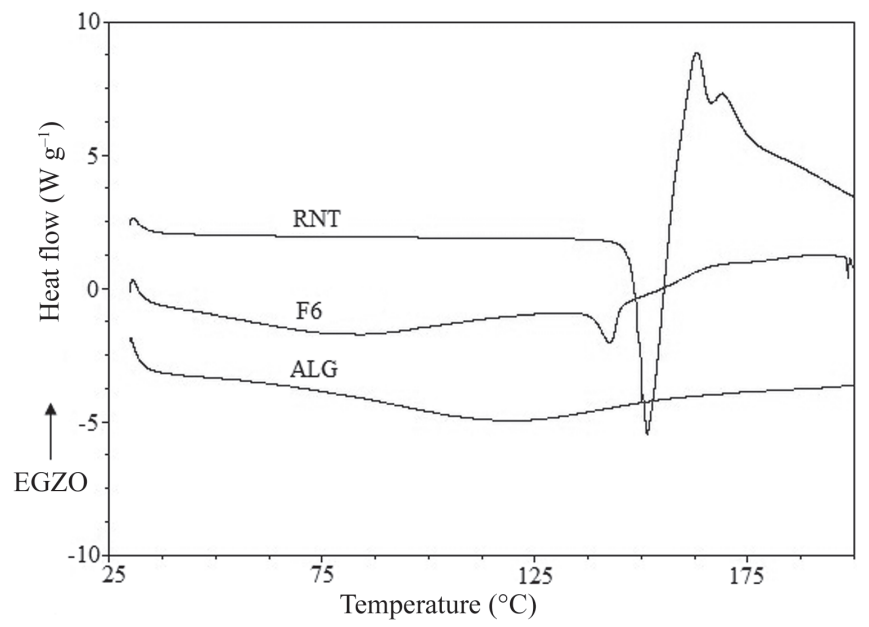

Fig. 5. DSC thermograms of RNT, ALG and microspheres formulation F6.

\section{CONCLUSIONS}

The obtained data suggest that mucoadhesive ALG microspheres with RNT can be successfully prepared by the spray drying technique. Properties of the obtained particles and RNT release can be altered by varying the drug/polymer ratio and concentration of the polymer solution. The optimum formulation of microspheres (F6) is characterized by the highest RNT loading, sustained drug release (up to $4 \mathrm{~h}$ ) and favourable swelling and mucoadhesive properties. The results of this study suggest that the designed microspheres could be effectively used as mucoadhesive carriers of RNT. Drug delivery via mucoadhesive microspheres is a promising area for continued research with the aim of achieving controlled RNT release with its enhanced bioavailability.

Acknowledgments. - This study was conducted with the aid of equipment purchased by the Medical University of Białystok as part of the OP DEP 2007-2013, Priority Axis I.3, contract No POPW.01.03.00-20-008/09 and supported by the Medical University of Białystok grant (134-15549F).

\section{REFERENCES}

1. A. R. Kumar and P. O. Katz, Functional esophageal disorders: a review of diagnosis and management, Expert Rev. Gastroenterol. Hepatol. 7 (2013) 453-461; DOI: 10.1586/17474124.2013.811028.

2. A. W. Basit and L. F. Lacey, Colonic metabolism of ranitidine: implications for its delivery and absorption, Int. J. Pharm. 227 (2001) 157-165; DOI: 10.1016/S0378-5173(01)00794-3.

3. M. F. Williams, G. E. Dukes, W. Heizer, Y. H. Han, D. J. Hermann, T. Lampkin and L. J. Hak, Influence of gastrointestinal site of drug delivery on the absorption characteristics of ranitidine, Pharm. Res. 9 (1992) 1190-1194.

4. A. D. Khan and M. Bajpai, Floating drug delivery system: an overview, Int. J. PharmTech Res. 2 (2010) 2497-2505. 
5. A. Streubel, J. Siepmann and R. Bodmeier, Gastroretentive drug delivery systems, Expert Opin. Drug Deliv. 2 (2006) 217-233; DOI: 10.1517/17425247.3.2.217.

6. M. D. Shadab, G. K. Singh, A. Ahuja, R. K. Khar, S. Babota, J. K. Sahni and J. Ali, Mucoadhesive microspheres as a controlled drug delivery system for gastroretention, Syst. Rev. Pharm. 3 (2012) 4-14; DOI: 10.4103/0975-8453.107130.

7. A. Kumar, S. Jha, R. Rawal, P. S. Chauhan and S. D. Maurya, Mucoadhesive microspheres for novel drug delivery system: a review, Am. J. PharmTech Res. 3 (2013) 196-213.

8. M. Shadab, A. Ahuja, R. K. Khar, S. Baboota, K. Chuttani, A. K. Mishra and J. Ali, Gastroretentive drug delivery system of acyclovir-loaded alginate mucoadhesive microspheres: formulation and evaluation, Drug Deliv. 18 (2011) 255-264; DOI: 10.3109/10717544.2010.536270.

9. H. H. Tønnesen and J. Karlsen, Alginate in drug delivery systems, Drug Dev. Ind. Pharm. 28 (2002) 621-630; DOI: 10.1081/DDC-120003853\%20.

10. K. N. Sachan, S. Pushkar, A. Jha and A. Bhattcharya, Sodium alginate: the wonder polymer for controlled drug delivery, J. Pharm. Res. 2 (2009) 1191-1199.

11. A. L. Ching, C. V. Liew, L. W. Chan and P. W. Heng, Modifying matrix micro-environmental pH to achieve sustained drug release from highly laminating alginate matrices, Eur. J. Pharm. Sci. 33 (2008) 361-370; DOI: 10.1016/j.ejps.2008.01.007.

12. P. Zentilin, P. Dulbecco, E. Savarino, A. Parodi, E. Iiritano, C. Bilardi, S. Reglioni, S. Vigneri and V. Savarino, An evaluation of the antireflux properties of sodium alginate by means of combined multichannel intraluminal impedance and pH-metry, Aliment. Pharmacol. Ther. 21 (2005) 29-34; DOI: 10.1111/j.1365-2036.2004.02298.x.

13. K. Cal and K. Sollohub, Spray drying technique. I: Hardware and process parameters, J. Pharm. Sci. 99 (2010) 575-586; DOI: 10.1002/jps.21886.

14. C. A. Lau-Cam, M. Rahman and R. W. Roos, Rapid reversed phase high performance liquid chromatographic assay method for ranitidine hydrochloride in dosage forms, J. Liq. Chromatogr. 17 (1994) 1089-1104; DOI: 10.1080/10826079408013387.

15. B. Arica, S. Calis, P. Atilla, N. T. Durlu, N. Cakar, H. S. Kas and A. A. Hincal, In vitro and in vivo studies of ibuprofen-loaded biodegradable alginate beads, J. Microencapsul. 22 (2005) 153-165; DOI: 10.1080/02652040400026319.

16. J. D. Clogston and A. K. Patri, Zeta potential measurement, Methods Mol. Biol. 697 (2011) 63-70; DOI: 10.1007/978-1-60327-198-1_6.

17. R. Shaikh, T. R. Raj Singh, M. J. Garland, A. D. Woolfson and R. F. Donnelly, Mucoadhesive drug delivery systems, J. Pharm. Bioallied Sci. 3 (2011) 89-100; DOI: 10.4103/0975-7406.76478.

18. S. J. Jackson and A. C. Perkins, In vitro assessment of the mucoadhesion of cholestyramine to porcine and human gastric mucosa, Eur. J. Pharm. Biopharm. 52 (2001) 121-127; DOI: 10.1016/S09396411(01)00156-4.

19. P. Stasiak, M. Placzek, P. Lepek and M. Sznitowska, Influence of polymer type, active substance, and experimental model on mucoadhesive properties of selected drug formulations, J. Disp. Sci. Technol. 32 (2011) 1780-1785; DOI: 10.1080/01932691.2011.616175.

20. E. Szymańska, K. Winnicka, A. Amelian and U. Cwalina, Vaginal chitosan tablets with clotrimazole - design and evaluation of mucoadhesive properties using porcine vaginal mucosa, mucin and gelatin, Chem. Pharm. Bull. 62 (2014) 160-167; DOI: 10.1248/cpb.c13-00689.

21. E. I. Nep and B. R. Conway, Grewia gum 2: mucoadhesive properties of compacts and gels, Trop. J. Pharm. Res. 10 (2011) 393-401; DOI: 10.4314/tjpr.v10i4.4.

22. The United States Pharmacopeia 35, National Formulatory 27, Vol. 1, The United States Pharmacopeial Convention, Rockville 2012, pp. 264-271. 
23. E. Szymańska and K. Winnicka, Preparation and in vitro evaluation of chitosan microgranules with clotrimazole, Acta Pol. Pharm. 69 (2012) 509-513.

24. P. Costa and J. M. Sousa Lobo, Modeling and comparison of dissolution profiles, Eur. J. Pharm. Sci. 13 (2001) 123-133; DOI: 10.1016/S0928-0987(01)00095-1.

25. J. Siepmann and N. A. Peppas, Modeling of drug release from delivery systems based on hydroxypropyl methylcellulose (HPMC), Adv. Drug Deliv. Rev. 48 (2001) 139-157; DOI: 10.1016/S0169409X(01)00112-0.

26. E. Mazurek-Wądołkowska, K. Winnicka, A. Czajkowska-Kośnik, U. Czyżewska and W. Miltyk, Application of differential scanning calorimetry in evaluation of solid state interactions in tablets containing acetaminophen, Acta Pol. Pharm. 70 (2013) 787-793.

27. P. Upadhyay, K. S. Khomane, L. Kumar and K. A. Bansal, Relationship between crystal structure and mechanical properties of ranitidine hydrochloride polymorphs, Cryst. Eng. Commun. 15 (2013) 3959-3964; DOI: 10.1039/C3CE40201K.

28. N. Chieng, Z. Zujovic, G. Bowmaker, T. Rades and D. Saville, Effect of milling conditions on the solid-state conversion of ranitidine hydrochloride form 1, Int. J. Pharm. 327 (2006) 36-44; DOI: 10.1016/j.ijpharm.2006.07.032.

29. N. R. Pani, L. K. Nath and S. Acharya, Compatibility studies of nateglinide with excipients in immediate release tablets, Acta Pharm. 61 (2011) 237-247; DOI: 10.2478/v10007-011-0016-4.

30. J. P. Soares, J. E. Santos, G. O. Chierice and E. T. G. Cavalheiro, Thermal behavior of alginic acid and its sodium salt, Ecletica Química 29 (2004) 57-64; DOI: 10.1590/S0100-46702004000200009. 